Reviews

Julian L. Simon.

1996. The Ultimate Resource - 2. Princeton, New Jersey: Princeton University Press.

(revised edition) 734pp.

\title{
Beyond Borders: Remaking Cultural Identities in the New East and Central Europe. Edited by Lazlo Kurti and Juliet Langman (1997) Boulder, CO, Westview Press, 160 pp.
}

\section{Reviewed by E. L. Cerroni-Long, Anthropology, S.A.C. Department, Eastern Michigan University}

One of the most striking outcomes of a three-day symposium on ethnicity, held at the 1998 International Congress of Anthropological and Ethnological Sciences, was the contrast in the proposals respectively advanced by the American and Russian delegations. While the American contributors voiced a strong recommendation for eliminating the term "race" from the social science discourse on ethnicity, the Russians expressed an equally strong belief in the need to eliminate the concept of nationality! The ironic symmetry of these statements illustrates particularly well the "cultural embeddedness" of our analytical procedures, and it highlights how certain terms and concepts acquire symbolic meanings that are very context-specific. The collection of articles put together by Lazlo Kurti and Juliet Langman in Beyond Borders, is a helpful introduction to this issue, and the fact that the volume's focus is the ethnocultural dynamics of post-1989 East and Central Europe gives it special immediacy.

In spite of the fashionable ring of the title, this book does not introduce - in one of the contributors' felicitous phrase - "another post-modern, globalized concerto" (p. 95). On the contrary, the various case studies it presents solidly document not only the persistence of ethnic identity in populations that have long been presumed "homogenized," but also the inevitability of separatist movements catalyzed by such identities whenever the political circumstances are favorable. The fact that the volume's goals seem to derive from quintessentially postmodern premises makes its conclusions all the more relevant. As the editors point out in their introduction, the book was designed to address the question: "Does globalization really result in an unprecedented integration of the life-ways of ordinary citizens in East and Central European cities and regions?" (p. 4).

Furthermore, the overall focus of the contributions is squarely centered on the issue of identity - that most postmodern of preoccupations. The case studies presented in the volume, however, answer the thematic question with a resounding "no" and consistently point out the remarkable strength, stability, and persistence of ethnic self-ascription in geographical settings and historical circumstances that could be expected to have obliterated it.

This paradoxical situation is described most cogently in one of the strongest pieces of the collection, Jonathan Schwartz's "Listening for Macedonian Identity" (pp. 95-110). In a chapter that effectively integrates ethnographic detail and complex historical information, the author sets out to describe the characteristics of a group of people whose sense of self is specifically correlated to experiences of "border crossing" and diasporic existence. In the words of Pecho, the Macedonian emigrant whose life history introduces the chapter: "In today's world you need two faces. ... I have four passports" (p. 95). The passports turn out to be Australian, Swedish, Yugoslavian, and Macedonian, and Pecho's life history is a veritable emblem of postmodern transnationalism. Nevertheless, as the author points out: "At no point in the narration is there any 


\section{Reviews}

doubt in Pecho's identity as a Macedonian" (p. 97).

But diasporic experiences - and the longing for a homeland that is all the more alluring for being partly fictional - are not the only factors behind the resilience of ethnic identity in Central and Eastern Europe. Juliet Langman's piece, focused on the identity of Hungarian youth in Slovakia (pp. 111-131), highlights particularly well the role played by language - and languagebased education - in confirming a sense of ethnic identity that is perceived as "given, primordial and unchangeable" (p. 114). Also, the author clearly explains how such strong identity may nonetheless become subsumed to state membership, no matter how shifting national boundaries may be. Thus the Hungarian youths Langman interviewed in Eastern Slovakia in the mid-1990s define themselves as first and foremost Hungarian, but they also reveal a strong attachment to their regional environment, which they fully recognize as being part of the Slovak polity (p. 118).

To further complicate matters, in Eastern and Central Europe the terms "ethnicity" and "nationality" do not have the same connotations they have in Western Europe or in the immigrant societies created by Western colonial expansion, such as Canada or Australia. This is an important point, which Langman illustrates in these terms: "... the Gypsies are considered an ethnic minority in Slovakia and Hungary as they have no 'home state,' while Hungarians in Slovakia and Slovaks in Hungary are considered nationalities" (p. 114). This is precisely the reason many Russian social scientists, as I mentioned above, find the concept of nationality so cumbersome. Culture, in its holistic anthropological meaning - involving expressions such as language, literature, art, or religion - has traditionally been correlated in Central and Eastern Europe with a territorial base, and - at least potentially - with an autonomous political organization. Consequently, the dilemma faced by Soviet communism has typically been how to accommodate the "local nationalism" of its republics within the framework of a political organization dominated by an ethnic group with national aspirations of its own. Thus, it could be argued that while Marxist ideology is internationalist, its political application has the best chance to succeed in settings in which it can be easily combined with solid forms of ethnonationalism.

This is not the perspective adopted by the compilers of Beyond Borders, who instead argue that "state socialism in its Soviet and East Bloc versions ... may be conceived of as a sort of failed globalism in which individual cultures were subsumed under the culture of the working man" (p. 5). This is a particularly naive statement, especially considering that at least one of the two editors specializes in cultural anthropology (one wonders what "the culture of the working man" could ever mean in anthropological terms). But, as mentioned above, while the documentation provided by this volume belies its assumptions, these seem to involve the postmodern fascination with globalization, transationalism, and hybridity. Indeed, the introductory piece refers reverentially to the views of culture of some of the high priests of postmodern orthodoxy, and such views throw very little light on the issue of ethnicity.

Another limitation of the volume derives from the fact that several of its contributors seem to take for granted a binary view of nationalism that is truly detrimental to clarifying ethnic dynamics. This view is described in Langman's piece as "the debate on what the basis of the nation should be: ethnos, 'the folk,' or demos, "the citizen" (p. 127). In a related note, the author goes on to say that these two views lead respectively to ethnic nationalism and geographic nationalism, and she argues that 18th century nationalism, as typically conceived in Europe at the time of the French Revolution, was of the latter type, while 19th century nationalism - as expressed, for example, in Germany or Hungary - was of the former (p. 131). In this view, the demos-based type of nationalism is perceived as "superior" as it permits to accommodate ethnic diversity within the context of a civil society in which rights are assigned to individuals rather than collectivities. In other words, it is a democratic and "modern" form of nationalism - as opposed to a tribal and atavistic one.

The belief that the "modern" nation is qualitatively different from its more ancient versions, and that it eschews and transcends an ethnic anchor, is totally unsupported by the anthropological evidence. The scholar who has addressed this issue most clearly in recent times is Anthony D. Smith, and his work points to the fact that the puzzlement expressed by many analysts about the 
Reviews

contemporary "re-emergence" of ethnicity may simply derive from a faulty understanding of what a nation is. In turn, this misunderstanding appears to be directly related to the continued influence on Western social science of unexamined modernist assumptions. It is quite ironic, then, that as non-Western scholars attempt to address the indigenous dynamics of ethnicity through the conceptual framework of postmodernism, they also reveal allegiance to modernist assumptions built on very Eurocentric, social evolutionist premises.

The profound ambivalence that characterizes the treatment of ethnicity in nation-states built upon egalitarian ideologies (and in this respect there are more similarities between political liberalism and state socialism than many Westerners would be comfortable to admit) can only be understood by realizing that they grew out of the very same philosophical roots from which the most virulent forms of ethnonationalism have also emerged. Western social science has translated this ambivalence into a set of myths about the processes that can "purify" the nation of its atavistic tendencies. The development of a healthy civil society is one of these processes, and a great portion of current literature on democratization focuses on it. The opening chapter in the Beyond Borders collection does, too, and while its author, Chris Hann, has written eloquently on the topic elsewhere, the Polish case study he presents here illustrates very well how democratizing processes do not necessarily benefit minority groups (p. 34). This is not surprising in light of the fact that, no matter how "healthy" their civil society, the greatest majority of contemporary states incorporate a cultural component - and a cultural component always intimates a hegemonic ethnic base.

Admittedly, the world has seen the emergence of some states that successfully encompass a number of cultural components. But examples of these "true" plural societies - cases such as Switzerland, Mauritius, or some Caribbean states - are few and very idiosyncratic. I would suggest that the "multiculturalism ideal" pursued by immigrant states such as Canada, and the "federalist ideal" being slowly implemented within the European Union, are two contemporary attempts at developing approaches that may be more generally applicable. Certainly, none of the case studies presented in this volume provides a model of successful management of ethnic diversity within a plural political framework. On the contrary, the volume emphasizes the real or potential destructiveness of cultural fragmentation. But then again, as Schwartz rightly points out: "Multiculturalism as a political goal is not native to the Balkan peninsula" (p.100). In fact, the term "Balkanization" has traditionally been associated with "political disorder, social fragmentation, and volatility, one which made Sarajevo in August 1914 not the mosaic, but the 'powder-keg of Europe'” (p. 100).

After the upheavals of 1989 to 1991, it may be legitimate to ask whether "Balkanization" may be a phenomenon likely to characterize all of Central and Eastern Europe, and, perhaps, even affect the stability - or civility - of long-established Western societies. This is perhaps the question at the real core of this volume, and at least one of the chapters - the final one, by Ruth Wodak openly addresses a version of it, by focusing on the effect on Austria of its "new minorities." The other chapters, with the exception of the introductory one, which is more theoretical and programmatic, limit themselves to describing the play of ethnic diversity in specific settings, giving special attention to the process of identity formation. Thus, Hann discusses the case of Lemko-Ukrainians in Poland, Crowther the Rumanian-speaking, ex-Soviet Moldovans, Todorova the Pomaks of Bulgaria, Shehu the trans-Albania Albanians, and Schwartz and Langman, as already discussed, the diasporic Macedonians and the Hungarians of Eastern Slovakia respectively.

The authors include three anthropologists, a political scientist, a historian, a psychologist, a linguist, and a writer who is also a locally-based political activist. The interdisciplinary character of the book, which includes seven chapters and a long introduction, is presented as a programmatic choice, as is the fact that some of the authors live in the areas they discuss and others are based in Western Europe or North America. However, the result is a general unevenness of tone, and a rather mixed quality of the writing. Still, as a documentary collection of case 
Reviews

studies, the volume is a valuable addition to the growing literature on a "new world disorder" that seems to be ever-expanding and intensifying.

\section{A Claim to Land by the River: A Household in Senegal 1720-1994. By Adrian Adams and Jaabe So, 1996. Oxford: Oxford University Press. 300 pp.}

\section{Reviewed by Olga F. Linares, Senior Scientist, Smithsonian Tropical Research Institute, Panama.}

A Claim to Land in the River chronicles the experiences of a Soninke family residing in one of many communities located along the Senegal River Valley: how its members attempt to forge a secure livelihood during two hundred years of frequent moves in village residence, shifts in land ownership and family practices, cycles in household composition and individual wage migrations. It is the story of at least eight generations of men and women in constant struggle against every conceivable adversity. These include natural disasters, the incursion of warring neighbors, colonial forms of taxation, and the post-independence policies of an overencompassing Senegalese State.

At stake nowadays is the right of numerous communities along the River to organize in defense of peasant farming. The Federation they have chartered seeks autonomy for its officers, so they can negotiate on behalf of community members for the kinds and amounts of loans and subsidies they need from hegemonic State agencies backed by foreign aid. On this Association lies the hope of many Soninke peasant farmers to master the technique of pump irrigation. Theirs is a complex production system combining flood recession farming with rain-fed cultivation further inland. To succeed in this unpredictable, drought-driven environment, the waters of the River must be harnessed. Their life-giving moisture needs to be managed efficiently, at the grass roots level, by experienced farmers who know the lay of the land and are fully committed to a participatory form of communal development. This, in essence, is the central message of this intriguing book. My purpose in the pages that follow is to provide a synopsis of the main events recounted in the book, and comment upon them. By doing so, I hope to guide the reader through the intricacies of a narration that involves various time-frames, many individual personalities and collectivities, multiple localities, numerous NGO's and State agencies and endless bureaucratic entanglements.

The main text of the story is built upon the narrations of individual Soninke actors. Principal among the speakers is the respected elder Jaabe So, the actual President of the Féderation des Paysans Organisés du Département de Bakel. His ancestors founded the community of Kungani on the left bank of the Senegal River. In the initial chapters, Jaabe So explains how the founders and their descendents brought the land under cultivation despite constant wars by neighboring warring factions, the threats of evil spirits, and the "tubab," with their superior ways. He recounts how founders allotted parcels to later-day arrivals until every section of riverine land was owned. Owners included the households of Muslim clerics, who farmed with help from their disciples, and households belonging to the descendents of village founders, or of their slaves. Jaaba So describes the farming practices of his father, Amma So. A dedicated farmer, Amma would cultivate maize and sorghum on the narrow strip of land along the inner bank of the Great River as the flood waters receded; then he would grow calabash and pumpkins further downslope, and also sweet potatoes and cowpeas, producing more than the family could eat.

Jaabe So's account of events from 1720 to 1938 is complemented by the voices of secondary actors, named individually. They fill in the story with further details concerning new waves of 